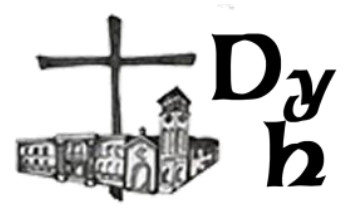

Síndrome de Burnout en sacerdotes

de una Diócesis de Argentina

Mgtr. Mariela R. Caraballo

Dios y el hombre, vol. 3, n. 2, e042, 2019

ISSN 2618-2858 - https://doi.org/10.24215/26182858e042

https://revistas.unlp.edu.ar/DyH/index

Cátedra libre de pensamiento cristiano - UNLP

Seminario Mayor San José

La Plata, Buenos Aires, Argentina

\title{
SÍNDROME DE BURNOUT EN SACERDOTES DE UNA DIÓCESIS DE ARGENTINA
}

\author{
Burnout Syndrome in Priests from a Diocese in Argentina
}

\author{
Mgtr. Mariela R. Caraballo \\ ottasara@yahoo.com.ar \\ Investigadora independiente - Río Cuarto - Argentina
}

\begin{abstract}
Resumen
El estudio tuvo como objetivo describir la presencia de Síndrome de Burnout en sacerdotes de una diócesis de Argentina. El Burnout es un problema que forma parte del ámbito de la salud y de la calidad de vida laboral. Se utilizaron tres instrumentos: el Maslach Burnout Inventory (MBI), un cuestionario sociodemográfico y entrevista en profundidad a dos grupos focales. En general, observamos en los sacerdotes que en la dimensión agotamiento emocional, el $19 \%$ se encuentra en un nivel bajo, el $57,1 \%$ en el nivel medio, y un $23,8 \%$ en el nivel alto. En la dimensión despersonalización, el 19\% se halla en un nivel bajo, el 61, 9\% en el nivel medio y el $19 \%$ alto. Por último, en realización personal, un $23,8 \%$ puntuó en el nivel bajo, un $47,6 \%$ en el nivel medio y un $28.6 \%$ en el nivel alto.
\end{abstract}

Palabras clave: Burnout, sacerdotes, estrés, salud comunitaria.

\section{Abstract}

The purpose of this study is to describe the presence of the Burnout syndrome in priests from the diocese in Argentina. The Burnout syndrome affects health and working life quality. Three main instruments were applied in this study: The Meslach Burnout Inventory (MBI), a socio-demographic questionnaire, and an in-depth interview to two focus groups. In general terms, it could be observed that in the emotional exhaustion dimension, the $19 \%$ of priests are in a low level, the $57,1 \%$ in a medium level and the $23 \%$ in a high level. In the depersonalization dimension, the $19 \%$ is in a low level, the $61 \%$ in a medium level and a $19 \%$ in a high level. Finally, regarding personal fulfillment, a $23,8 \%$ marked a low level, a $47,6 \%$ a medium level and $28,6 \%$ a high level.

Key words: Burnout, priests, stress, community health. 


\section{Introducción *}

El Burnout es un problema que forma parte del ámbito de la salud y de la calidad de vida laboral. Para Neira, M. (2004) es un tipo de estrés crónico que se define como una respuesta psicofísica que se produce en el sujeto, como consecuencia de un esfuerzo constante, ante lo cual la persona reacciona quedándose agotada, con sensación de indefensión y generalmente con retirada psicológica y muchas veces física de su actividad como consecuencia de este estrés excesivo. Los efectos del desarrollo del Burnout en el sujeto, se visualizan a través del nivel individual y del contexto laboral. A nivel individual, los cambios son observables físicamente (cansancio, debilidad, trastornos del sueño y de la alimentación, perturbaciones somáticas); emocionalmente (agresividad, ansiedad, tristeza, culpa, baja autoestima y baja tolerancia a la frustración); intelectualmente (perturbaciones en el juicio, en la memoria, en la concentración) y conductualmente (consumo de fármacos, conflictos personales y relacionales, etc.). En cuanto al contexto laboral, las consecuencias aparecen a través de un aumento del ausentismo, de errores, de relaciones interpersonales conflictivas, con incumplimiento de tareas, con pedidos anticipados de jubilación, entre otros. Gil Monte, P. et al (1998) sostienen que el Síndrome de Burnout, presenta síntomas tan numerosos que dificultan su delimitación conceptual, pero se puede confirmar que los mismos perjudican tanto afectos y emociones (agotamiento emocional, irritabilidad), cogniciones (baja autoestima, baja realización personal), actitudes (despersonalización, hostilidad), conductas (aislamiento, aumento de accidentes, conductas agresivas), y sistema fisiológico (cansancio, insomnio, entre otros) del sujeto, y los signos estarían conformados por el agotamiento emocional, la despersonalización y la falta de realización en el sujeto. ${ }^{1}$

Los sacerdotes, en tanto agentes comunitarios, son receptores de múltiples y variadas consultas de los fieles de su comunidad. Se puede decir que actualmente, tanto la Iglesia como los mismos sacerdotes, enfrentan el reto de funcionar en una sociedad cada vez más secularizada, que plantea grandes

\footnotetext{
* N. del Ed.: se ha omitido el nombre de la diócesis donde se realizó el estudio por una decisión editorial. Para más datos sobre el estudio realizado, comunicarse directamente con la autora.

${ }^{1}$ En mi opinión, ya que el síndrome en cuestión no forma parte de los nomencladores de la APA y la OMS, se debería hacer alguna mención al respecto acerca de las razones sobre esta exclusión.
} 


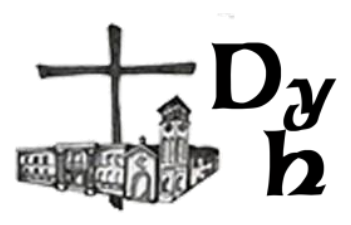

demandas debido a los cambios y a la pluralización de los valores. Por tanto, el ser conscientes de sus limitaciones y carencias humanas resulta fundamental para los sacerdotes (Conferencia Episcopal de Chile, 2008).

El síndrome de Burnout se ha estudiado en diferentes grupos de población, pero no lo suficiente en sacerdotes diocesanos. Por ser éstos, en la mayoría de los casos, individuos tan ocupados, tan expuestos a la gente y a los conflictos que experimentan los laicos, y con grandes exigencias propias de su vocación apostólica, se ha considerado importante investigar la incidencia de este síndrome en sacerdotes de una Diócesis de Argentina. Para ello, se aplicó el Maslach Burnout Inventory (MBI), y además un cuestionario de contextos y datos personales para indagar edad, antigüedad, actividades de comunidad, etc.

\section{Desarrollo}

El Síndrome de Burnout se manifiesta como resultado del estrés laboral crónico. Se trata de una experiencia subjetiva de naturaleza negativa, formada por emociones y conductas nocivas hacia las personas con las que se vincula el individuo en su trabajo, y hacia el propio rol laboral. Como consecuencia de esto, surgen en el sujeto, un conjunto de disfunciones psicológicas, fisiológicas y conductuales que van a repercutir en la persona y en la organización de un modo perjudicial (Gil Monte P. 2006). Maslach, C et al (1987) agregan que el Burnout se compone de tres factores o indicadores para la presentación del síndrome:

- Cansancio Emocional: considerado como desgaste, agotamiento, que puede presentarse a nivel físico, psíquico o bien como sensación de no tener más nada que brindar, tanto en lo profesional como en lo afectivo.

- Despersonalización: se observa a través del cambio que se produce en las actitudes y respuestas hostiles dadas por la persona, seguido de irritabilidad, distanciamientos, pérdida de la motivación laboral, cinismo, oposición, y rivalidad dirigida hacia las personas.

- Sentimiento de inadecuación y disminución de la realización personal en el trabajo: conformado por conductas negativas hacia sí mismo como hacia su labor, sensaciones de inadaptación, baja productividad y baja autoestima, valorándose negativamente. 
Gil Monte, P. et al (1998) consideran que el Burnout se inicia con la baja realización personal y un alto agotamiento emocional en el trabajo, y que la despersonalización formaría una estrategia de afrontamiento del trabajador. Estos autores plantean que el Burnout es una respuesta al estrés laboral crónico que incluye sentimientos displacenteros y actitudes negativas hacia el trabajo, y las personas con que se trabaja, que aparece cuando fallan las estrategias funcionales de afrontamiento que suele emplear el sujeto. Los estresores laborales pondrán en marcha estrategias de afrontamiento que deberán ser efectivas para eliminar las fuentes de estrés o para manejar las respuestas del individuo frente a las mismas; cuando no resulten exitosas y esto se mantiene de manera crónica, surge la baja realización personal en el trabajo y el agotamiento emocional, ante los cuales el sujeto desarrolla actitudes de despersonalización como nueva forma de afrontamiento. El Síndrome se identifica como un mecanismo de afrontamiento y autoprotección frente al estrés producido por la relación del profesional con las personas/pacientes, y por la relación profesional-organización. Esto genera sensación de fracaso tanto a nivel profesional como así también en las relaciones interpersonales con las personas/pacientes.

Como se dijo anteriormente, el síndrome de Burnout es altamente prevalente en aquellas personas que trabajan en los ámbitos de salud y/o comunitario (consejeros, sacerdotes, enfermeros, médicos, psicólogos, entre otros.). Al respecto Facal-Fondo, T (2012) llevó a cabo la investigación Prevalencia del Síndrome de Burnout en Trabajadores Sociales de los Servicios Sociales Comunitarios, el objetivo general de la investigación fue medir la prevalencia del Síndrome de Burnout en los trabajadores de servicios sociales comunitarios de la comarca de Santiago de Compostela. Dicho estudio se llevó a cabo con un diseño descriptivo transversal, utilizando como instrumento principal el cuestionario MBI-HSS (Maslach Burnout Inventory - Human services survey). Los resultados del mismo fueron que el $66.7 \%$ de los trabajadores presentan grados elevados de Burnout en alguna de sus tres dimensiones, siendo la dimensión que predomina, el Agotamiento Emocional (AE).

Actualmente, vivimos una época de globalización, proceso que no se puede asociar sólo con la actividad económica, ya que influye en todas las esferas de la actividad humana. Los rápidos cambios sociales, económicos y 


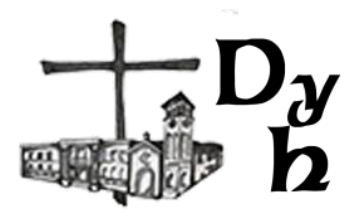

culturales con llevan grandes desafíos que inciden fuertemente en los sacerdotes. Hay una búsqueda de las cuestiones trascendentes en todas sus expresiones, pero hoy en día tal búsqueda parece ser más individualista, obviando la dimensión comunitaria en la realización espiritual. Como resultado de todos estos cambios, la acción de la Iglesia ha sufrido una importante desvalorización, y la imagen social de los sacerdotes ya no es aquella imagen idealizada de tiempo atrás.

Esta situación enfrenta a los sacerdotes con nuevos retos que les obligan a la integración de sus dimensiones físicas, psicológicas y espirituales. Por tanto, el ser conscientes de sus limitaciones y carencias humanas, resulta fundamental para los sacerdotes. Muchas veces, los miembros de la comunidad recurren a ellos en busca de respuestas que, de algún modo, van más allá de la dimensión espiritual. Por este motivo requieren de una adecuada formación humana, espiritual, comunitaria, académica y pastoral. Toda esta formación debe posibilitarles ser eficaces en sus tareas que se le ha encomendado; y en la base de todo esto debe haber una fuerte identidad sacerdotal que les permita interrogarse por los cambios socio-culturales (López, H 2011).

Zanotti, A (2013) en su libro Pensar las Crisis en la vida sacerdotal y consagrada, plantea que los seminarios han formado a lo largo de la historia a sujetos en vías de extinción, para evangelizar una sociedad que ya no existe en sus aspectos más íntimamente relacionados con la catequesis impartida. Esta situación produjo generaciones de sacerdotes insuficientemente preparados para la misión que debían afrontar. Algunos de los problemas que aquejan a los sacerdotes, según la autora, son: la soledad y aislamiento, dificultades en la convivencia, de comunicación entre hermanos y obispos, manifestaciones de conductas disociadas como la doble vida, manejo del dinero, del poder, etc. Por otra parte, los sacerdotes se encuentran en constante relación con la comunidad, para lo que se requiere un cierto grado de organización, complejidad y apertura hacia la misma.

Cozzens, D (2000) en su libro The Changing Face of the Priesthood, escribe acerca de la crisis sacerdotal, dentro de la que se encuentra la búsqueda progresiva de identidad como siervo de Dios. Esto último, impregna todos los aspectos de su vida: su mismo porte y conducta, la forma de comunicarse y relacionarse, la manera en que se dirige a los feligreses, amigos, etc. Con 
independencia de cuán disciplinada pueda ser la vida de oración y cuán comprometido el ejercicio del ministerio, el desarrollo humano del sacerdote constituye siempre un factor determinante del éxito o el fracaso de sus esfuerzos por alcanzar integridad, sentido y realización.

El propósito de este trabajo consiste, por tanto, en fundamentar la necesidad que tienen las personas dedicadas al ministerio sacerdotal de una mayor calidad de vida, por medio de un buen autoconocimiento y autocuidado, dentro del contexto de sus realidades sociales y eclesiales. Esto último permitiría un más eficiente servicio, por parte de ellos, hacia la sociedad, y en un enriquecimiento de su vida personal. Asimismo, se pretende generar sugerencias de estrategias para el autocuidado de los sacerdotes en el ámbito eclesial. El síndrome de Burnout se ha estudiado en diferentes grupos de población, pero no lo suficiente en sacerdotes diocesanos. Por ser éstos, en la mayoría de los casos, individuos sumamente ocupados y expuestos a los conflictos que experimentan los laicos, y con grandes exigencias propias de su vocación apostólica, se ha considerado importante detectar la presencia de este síndrome en sacerdotes de una diócesis de Argentina.

\section{Metodología y Materiales}

La investigación tuvo como objetivo describir la presencia del síndrome de Burnout en sacerdotes de una diócesis de Argentina, para lo cual se tomó una muestra de 22 sacerdotes a los que se les aplicó en un primer momento el MBI y un cuestionario sociodemográfico, y en un segundo momento se realizaron entrevistas en profundidad a dos grupos focales. La principal dificultad presentada en el trabajo fue al momento de la recolección de datos, ya que de 80 sacerdotes con que cuenta la Diócesis, sólo 22 respondieron los cuestionarios. Por este motivo, se utilizó la estrategia de entrevistas en profundidad.

\section{Resultados}

Los resultados se hallan en el mismo sentido de las investigaciones que se han indicado como antecedentes del trabajo. Como ya se mencionó, se encontró que en los sacerdotes de la Diócesis, en la dimensión agotamiento 


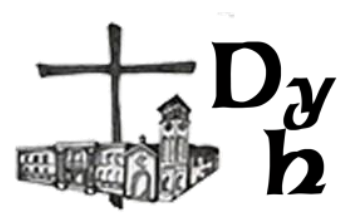

emocional, el $19 \%$ se encuentra en un nivel bajo, el 57,1\% en el nivel medio, mientras que un 23,8\% en el alto. En la dimensión despersonalización el $19 \%$ se halla en un nivel bajo, el 61,9\% en el nivel medio y el $19 \%$ en el alto. Por último, en realización personal, un 23,8\% puntuó en el nivel bajo, un 47,6\% en el nivel medio y un $28.6 \%$ en el nivel alto.

López, H (2011), en su investigación Incidencia del síndrome de burnout en sacerdotes católicos latinoamericanos y su relación con la inteligencia emocional, halla que en la subescala de agotamiento emocional el 34,8\% de los sacerdotes encuestados registra puntuaciones menores o iguales a 14 , lo que equivale a decir que esos individuos presentan puntuaciones óptimas para esa escala. Sin embargo, el 65,2\% presenta valores de agotamiento emocional medios y altos, por tanto, en comparación con los demás hallamos valores de medio a alto en esos mismos sacerdotes, lo que significa que sí se encuentran agotados emocionalmente. En este sentido podemos decir que en los sacerdotes de la Diócesis de este estudio, los porcentajes también se encuentran entre valores medios y altos de agotamiento emocional y despersonalización. La diferencia está en que éstos presentan además valores altos en realización personal.

Al respecto, se recuerda que Maslach, C et al (1981) establecen en su modelo como primera etapa del desarrollo del Burnout la manifestación de agotamiento emocional, este es el elemento central en el síndrome, y considera que la falta de realización personal aparece paralelamente, generando ciertos estresores de tipo interpersonal. Las actitudes de despersonalización hacia los destinatarios del servicio sería un intento de manejar los sentimientos de agotamiento emocional, repercutiendo en la implicancia del trabajador en la labor. A su vez reiteramos que Gil Monte, P et al (2005), desarrollaron otra alternativa, la cual sostiene que los sentimientos de baja realización personal y los de agotamiento emocional, son las primeras respuestas al estrés, y la despersonalización aparece como una estrategia de afrontamiento ante la cronicidad de los primeros síntomas. La baja realización personal, entonces, aparece, para algunos autores, como pieza clave para la generación del síndrome de Burnout, mientras que para otros, el agotamiento emocional. 
La postura psicosocial considera el Burnout como un proceso donde aparecen síntomas como primera manifestación ante el estrés laboral. Al respecto, los sacerdotes de la Diócesis de la muestra del presente trabajo manifestaron presentar diversos síntomas, tanto de orden emocional como físicos (soledad, amargura, desánimo, respuestas violentas, dolor de cabeza, apatía y decepción, insomnio, gastritis, sensación de estar sobrepasado, agotado, dolor abdominal, palpitaciones y dolor de pecho, angustia, miedo, cansancio, irritabilidad, tristeza, ansiedad, sentimientos de fracaso, olvidos, distracción, depresión, comer en exceso, enojo, desazón, desaliento, ahogo, falta de aire). Dentro de estos síntomas expresados, las respuestas violentas, la apatía y sentimientos de fracaso, responden a los síntomas que caracterizan a la despersonalización. Recordamos que en este sentido López, H (2011), afirma que los sacerdotes fallan, se agotan o quedan exhaustos emocionalmente, debido a que se involucran excesivamente en su trabajo llegando a ser ineficaces para el desempeño. Concluye que esto provoca en los sacerdotes el síndrome de Burnout, el cual debe ser entendido como un trastorno psicosocial en el trabajo. Dicha afirmación se pone en evidencia en los relatos de los sacerdotes de esta Diócesis de Argentina al mencionar la multiplicidad de tareas, las excesivas demandas de la comunidad, y los sentimientos negativos que estas les generan.

López, H (2011) en su investigación describe cuáles son las relaciones de valores entre las dimensiones de Burnout que generan el síndrome. Así, si la despersonalización puntúa en la categoría más baja, independientemente de lo que pase en las demás dimensiones, ya podemos asegurar que el sujeto o no está desgastado o se clasifica en el nivel intermedio. Si la despersonalización está en máximos, lo más probable es que el sujeto esté en la categoría "muy quemado", aunque si la Autoestima no es muy baja puede ser que el sujeto se clasifique en la categoría de intermedios. El agotamiento tiene un comportamiento similar, donde vemos que la Autoestima juega un papel moderador claro. De la misma manera, si el agotamiento está en grado alto y la realización personal baja, el sacerdote presenta el Burnout en grado máximo. Si el agotamiento está en grado alto y la realización personal se encuentra en grado medio o alto, el sacerdote sufre de Burnout en grado medio. Si el agotamiento se encuentra en grado medio todos se encuentran desgastados 


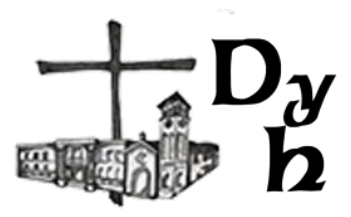

independientemente de la realización personal, pero si el Agotamiento es bajo, sufren de desgaste profesional intermedio independientemente de la Realización Personal.

La autora concluye diciendo que si presentan el agotamiento en alto grado, pertenecen a la clase de Burnout intermedio independientemente del grado de realización personal. Si el agotamiento emocional clasifica en grado medio o bajo no presentan Burnout independientemente del grado de realización personal. Y que tradicionalmente se clasifica a los sujetos en grado de desgaste alto, medio o bajo según si los valores que tome en desgaste, autoestima y despersonalización pertenecen a cada una de esas categorías, pero en la práctica nos vamos a encontrar a menudo con que un sujeto, en este caso un presbítero, puede tener valores máximos de agotamiento y estar en el intervalo más bajo de despersonalización y en el más alto de autoestima; o estar en el más bajo de autoestima y en el más bajo de agotamiento, pero en el intermedio de despersonalización, o cualquier otra de las combinaciones posibles.

Basándonos en estas consideraciones, podemos inferir que los sacerdotes de nuestro estudio sufren niveles de Burnout que van de medio a alto, ya que, como se dijo al principio, el $57 \%$ se encuentran dentro de los niveles medios y el $24 \%$ dentro de los altos. Recordemos que en esta muestra los niveles de realización personal van de medio a alto, sin embargo al respecto López, H (2011), según su investigación, en los sacerdotes los valores de autoestima profesional o realización personal no presentan un patrón concreto. En función de esto último, se puede deducir, entonces, que en los sacerdotes de nuestro estudio la incidencia del síndrome de Burnout constituye una amenaza importante para ellos.

Paredes, M (2001), demostró, estudiando una amplia muestra de profesores universitarios, que para estar en la categoría de Burnout más alto no es necesario tener las tres dimensiones en los valores extremos. Si tomamos en cuenta esto último vemos que si bien los niveles en los sacerdotes de la Diócesis no se encuentran todos en su puntuación máxima, los relatos desarrollados por ellos en los grupos focales corroboran que se encuentran desgastados al especificar sus molestias, como ellos mismos lo definen, ante la superposición de tareas, los roles variados y pocos definidos, y aquellas actividades que 
"tienen" que realizar más allá de que les desagrade. En nuestro trabajo hallamos que la edad media de esta muestra que presenta mayores niveles de Agotamiento y Despersonalización es de 44 años, mientras que aquellos sacerdotes con una edad mayor de 50 presentan niveles medios de Agotamiento y Despersonalización, y niveles altos de Realización Personal. Reiteramos la importancia de niveles aceptables de Realización Personal que pueden ser considerados como un factor protector. Es decir que las edades que más puntuaron se encuentran un poco por debajo respecto a los sacerdotes de la presente Diócesis de Argentina.

Se encontró también que los años de sacerdocio influyen en los niveles de Agotamiento y Despersonalización, siendo la franja de 16-30 años de sacerdocio, la que presenta niveles medios y altos. Al respecto, en una investigación realizada por Alves, F (2008), en Brasil, con 103 sacerdotes formadores de seminaristas, de ellos, 78 diocesanos y 25 religiosos, se encontró que los sacerdotes con edades comprendidas entre 27 y 37 años son los que presentan mayor Agotamiento Emocional, 43,8\%, lo que significa que un 39,7\% de los mismos están agotados en alto grado. Otro factor que aparece como influyente en el desarrollo de Burnout en los sacerdotes de nuestra muestra son los años de permanencia en una misma Iglesia o Parroquia. Estos resultados fueron reforzados con lo manifestado por los grupos focales, quienes hicieron referencia a las rotaciones o cambios cada seis años, expresando la mayoría de ellos su disconformidad al respecto.

Por lo tanto si hacemos una lectura de los resultados cuantitativos vemos que quienes se encuentran dentro de los 8 años de permanencia presentan mayores niveles de Burnout. Esto último puede deberse a la inestabilidad que les genera el no saber en qué momento se tienen que mudar. Sabemos que toda mudanza o cambio da lugar a un proceso de duelo que debe ser elaborado, como así también puede dar lugar a altos niveles de estrés. En este sentido recordamos que se han identificado ciertos estresores como influyentes en el síndrome de Burnout, pertenecientes tanto al ámbito social como al laboral y el personal. Los desencadenantes laborales son considerados relevantes en relación al desarrollo del síndrome. Y si retomamos a Peiró, J et al (2002), respecto a dichos desencadenantes, sabemos que pueden agruparse como aquellos pertenecientes al ambiente físico y a los contenidos del puesto 


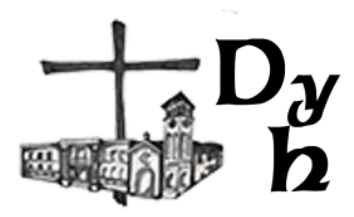

laboral, incluyendo condiciones como el ruido, las malas condiciones físicas del lugar de trabajo, rotación de turnos, etc. Es decir que aquella variable "años de permanencia en una misma parroquia" puede ser considerada como un factor estresor perteneciente al contenido laboral.

Por último, se analizó la variable actividades comunitarias en relación a las dimensiones de Burnout, y encontramos que los sacerdotes de la Diócesis de Argentina investigada se encuentran también en su mayoría dentro de los niveles medios y altos de Agotamiento y Despersonalización, aunque los niveles de Realización Personal fueron también de medio a altos. Si retomamos los relatos de los grupos focales, podemos suponer que más que la tarea en sí, lo que parece llevarlos a niveles altos de Despersonalización y Agotamiento es la superposición dichas tareas. Esta conclusión resulta del análisis de las entrevistas en profundidad, ya que, paradójicamente, aquellas tareas que agotan son las mismas que les provocan satisfacción al preguntárseles acerca de las actividades que les agrada. La única actividad en la que todos coincidieron que les provocaba disgusto es la administrativa.

A comienzos del presente trabajo, se hizo referencia a Precht, C (2002) quien señala que de igual manera es frecuente encontrar cansancio en la vida de los sacerdotes, unos por el exceso de trabajo y otros por un cansancio crónico, causado por el estilo de vida. En este sentido recordamos a Crea (2012), que sostiene que, en la labor pastoral, trabajar significa involucrarse demasiado, siendo esto un riesgo de implicarse en situaciones difíciles de resolver. Esta superposición de tareas puede llegar a ser generadora de altos grados de estrés. En esta perspectiva, Strazdins, L (2002) en su artículo Emotional work and emotional contagion, manifiesta que en las últimas décadas se ha producido en el mundo occidental una serie de cambios sociales que han afectado a las organizaciones, a las ocupaciones y a los trabajadores, y que han contribuido a la aparición del síndrome de Burnout. Este desequilibrio en la demanda también obliga a los profesionales a realizar tareas para las que no han sido formados y consecuentemente sufren conflicto y ambigüedad de roles.

Numerosos estudios muestran que el trabajo con personas y las relaciones con ellas, en especial si presentan problemas personales o familiares, suelen ser una fuente importante de estrés para los profesionales. En este sentido, recordamos que Schaufeli, W et al (1993), plantea como uno de los 
niveles de factores estresores el interpersonal, y se refiere a estresores tales como relaciones tensas, conflictivas y prolongadas tanto con los usuarios del servicio como con los compañeros de trabajo; a la falta de apoyo de compañeros y directivos de una organización, a la excesiva identificación del trabajador con el usuario y el conflicto con éste o sus familiares. Zanotti, A (2013), nos dice que el presbítero no es un "superhombre", ni es un ser extraterrestre, sino un hombre de carne y hueso, con las limitaciones y miserias propias de la condición humana, incluso con las heridas que va dejando la vida en su trama dramática. En esta perspectiva, los sacerdotes continúan mencionando actividades que les provocan angustia, dolor y desgaste, pero que consideran es su responsabilidad hacerlas. Se relatan nuevamente las diferencias que surgen entre sus pares.

Como ya se ha expresado, entre los factores laborales que favorecen el desarrollo del síndrome de Burnout, López, H (2011) señala la pérdida de tiempo en tareas burocráticas o administrativas, las expectativas irreales, la falta de límites en el desempeño de funciones, la ambigüedad de tareas, la falta de control en el trabajo y la falta de reconocimiento. A su vez, Melguizo (2002) plantea que todas estas causas de estrés negativo minan la salud física y psíquica, conduciendo a los sacerdotes más vulnerables a experimentar los síntomas del estrés crónico. La autora destaca que los sacerdotes presentan problemas derivados de situaciones de soledad y aislamiento, de convivencia, dificultades de comunicación entre los presbíteros y con los obispos. También suelen darse manifestaciones de conductas disociadas, en cuanto al manejo del dinero, del poder, por ejemplo, también cierta hiperactividad, crisis afectivas, agobio por el peso de lo institucional, estados de desánimo y sentimientos de impotencia para afrontar dichas situaciones. Estas afirmaciones coinciden con las reveladas por los sacerdotes del presente estudio. Zanotti, A (2013) continúa diciendo que las tareas administrativas representan las funciones del control del sistema. En toda organización (en este caso, la Iglesia) se cumplen tareas básicas que representan los propósitos para lo cual fue creada (la misión). Para llevar a cabo estas tareas básicas, la organización debe crear y proteger una atmósfera óptima (clima emocional) que supone la gratificación de las necesidades humanas en el curso de la consecución de las tareas específicas de la organización. 


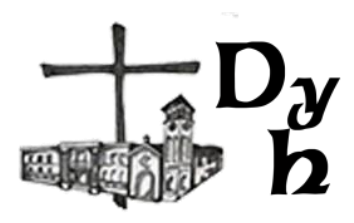

Al respecto, los presbíteros vuelven a expresar el hastío provocado por las tareas administrativas ya que en la mayoría de los casos no cuentan con la ayuda necesaria. Expresan el cansancio que les genera las excesivas demandas de los fieles. Además plantean la preocupación por los escasos ingresos que logran recaudar, ya que los sacerdotes, según ellos manifiestan en las entrevistas, no tienen ingresos fijos o sueldos, derivando esto en una preocupación propia de la crisis vital que puede devenir con la jubilación y la vejez. Numerosos autores (Herrera H 2011, Gil-Monte et al 1998, Strazdins, L. 2002) coinciden en que la sobrecarga laboral, la falta o excesiva variedad de tareas, las relaciones formales tanto con los compañeros, como con las autoridades y los destinatarios del servicio a brindar, la falta de cohesión grupal, el contacto directo con una enfermedad, con el dolor y con la muerte y, por último, la pérdida de tiempo en tareas burocráticas o administrativas, la falta de límites en el desempeño de funciones, la ambigüedad de tareas, son todas generadoras de Burnout.

En el cuestionario sociodemográfico (DSD), al indagar acerca de si recuerdan alguna situación en la que se hayan sentido sobrepasados, expresan que aparentemente se hicieron evidentes al desencadenarse algunos "problemas de visión, situaciones emocionales y dificultades que los llevaron a sentirse saturados, por ejemplo a fin de año. Los conflictos con otros sacerdotes, dificultades con los empleados (secretarias, empleada doméstica) cansancio por asuntos personales, falta de responsabilidad de los fieles en la coordinación de los grupos y ejecución de tareas", son situaciones que describen como aquellas que les provocó esta sensación. Además, manifestaron que el hecho de coordinar muchas cosas a la vez les provoca saturación, siendo otras de las situaciones las crisis personales y comunitarias, el no sentirse aceptado, la sensación de querer huir como manifestación del cansancio. También sienten una exigencia constante en las tareas a realizar sobre todo al imponer autoridad a los diferentes grupos. Sufren la disconformidad e indiferencia de algunos fieles, las críticas infundadas (ya sea de parte de la comunidad como de parte de otros sacerdotes). También expresaron que el acompañamiento a familias que han perdido su hijo, les provoca a algunos la sensación de agotamiento o el hecho de escuchar situaciones complicadas. Uno de los sacerdotes destaca que en una ocasión era tanto el sentimiento de 
sobrecarga que tenía que se le manifestó ataques de pánico en la celebración de la misa. Respecto a la imagen que la sociedad tiene de los sacerdotes, y éstos de sí mismos, es una variable que ellos consideraron de importancia en cuanto a generadora de presiones.

Grün, A (2013) expresa que "las imágenes que son impuestas desde afuera pueden ser agotadoras", como así también el pretender complacer a todos, por parte de los sacerdotes. Afirma que muchas veces son "imágenes que paralizan y roban la energía". Este concepto de imaginario social, se emparenta con los "marcos" que conforman desde las metas, formas de actuar y valorar, hasta la política y las instituciones. Lakoff, G et al (2012) plantean que los marcos son estructuras mentales que conforman nuestro modo de ver el mundo. En síntesis, pareciera que en los presbíteros, el relacionarse con los miembros de la comunidad, como así también el contacto diario con el sufrimiento, el ocuparse de su salud espiritual, el tener una jornada de trabajo sin horarios, el enfrentarse a situaciones irresolubles, o situaciones organizativas inadecuadas, disfuncionales e incluso no equitativas, provoca, en muchos casos, síntomas físicos y emocionales que deberían ser abordados adecuadamente. Estos factores aparecen reflejados en las manifestaciones de los grupos focales de los sacerdotes de la Diócesis de Argentina, objeto de la presente investigación, mencionándose además el peso que cobran algunas actividades con el paso de los años y las preocupaciones respecto a la vejez y la jubilación.

Desde esta perspectiva, López, H (2011), en su estudio sobre el Burnout en sacerdotes, señala que las personas en su proceso de madurez, durante el ciclo de vida, requieren de una comprensión positiva de sí mismas, al igual que una relación satisfactoria con quienes le rodean y que le dan sentido de pertenencia y sólido sentido de misión. En función de esto se considera importante el acompañamiento espiritual y profesional a aquellos sacerdotes que se encuentren atravesando por diferentes crisis vitales, siendo éstas potenciales generadoras del síndrome. Recordando entonces que el síndrome de Burnout se define por la interrelación de factores individuales, laborales y sociales, en el análisis de lo manifestado por los sacerdotes de la Diócesis de Argentina del presente estudio, se puede ver que hay una convergencia de aquellos, ya que la mayoría de los sacerdotes realizan todas las tareas 


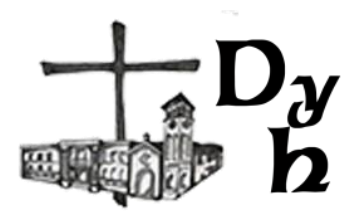

comunitarias juntas, con o sin agrado. Los sacerdotes parecen encontrar en la realización de las mismas una multiplicidad de factores estresores que hacen que se hallen en niveles medios y altos de Burnout.

Al respecto, y basándose en los resultados de su investigación, López, $H$ (2012) concluye que: "El ejercicio sacerdotal se ha hecho cada vez más difícil y complicado. Las exigencias crecientes de la demanda social han incrementado el esfuerzo, la tensión y la sobrecarga diaria que el sacerdote debe afrontar. La relación con los fieles, el contacto diario con los que mueren y sufren, la responsabilidad sobre la salud espiritual de terceros, una jornada de trabajo sin horarios que se alarga mucho más que la de cualquier otro ciudadano, el enfrentamiento a situaciones irresolubles, la tremenda soledad en la que muchas veces viven, situaciones organizativas inadecuadas, disfuncionales e incluso no equitativas, son un panorama frecuente en este colectivo". En función de todo lo descripto, y retomando la Ley de Salud Mental, reiteramos la importancia de hacer evidente con el presente estudio la imperiosa necesidad de ocuparnos de la salud de los sacerdotes ya que el este contexto de dicha Ley, son considerados como agentes comunitarios clave. Es en este sentido que nuestro objetivo tiende a generar un aporte -aunque mínimo, no menos importante- a la Ley 26.657, siendo los sacerdotes recursos con los que se cuenta para una atención no formal de aquellas personas que no pueden acudir a los centros especializados. Por lo tanto se torna vital que se los forme para las intervenciones que realizan, ya que juegan un papel importante con sus aportes a la comunidad. Por ello, se ha planteado que, debido a los nuevos desafíos, conocimientos y realidades, se torna necesario renovar y fortalecer la APS utilizando al máximo las capacidades y potencialidades disponibles.

En este contexto, el desarrollo de los recursos humanos es una pieza esencial y estratégica. Desde esta perspectiva, se consideran a los sacerdotes como agentes clave de la comunidad puesto que reciben numerosas consultas de las personas en torno a padecimientos emocionales y que, ante la falta de formación en la temática, se les dificulta su identificación, derivación y hasta intervención en situaciones de crisis. Numerosos autores coinciden en la importancia de la formación de sacerdotes como un factor protector. Al ocupar un lugar clave en la sociedad, estudiar y profundizar en sus niveles de Burnout, 
apuntan a la prevención en sí, colaborando así en la salud mental de los sacerdotes y potenciando sus herramientas para las intervenciones comunitarias.

Dicho esto, es evidente que considerar la salud mental y física de los sacerdotes como agentes no formales, es una manera de mejorar los servicios de atención en salud. En este sentido, la OMS plantea que "para todas las personas, la salud mental y física y el bienestar social, son componentes vitales inextricablemente ligados. Con el desarrollo del conocimiento acerca de esta interrelación, surge más claramente que la salud mental es crucial para asegurar el bienestar general de los individuos, sociedades y países. Entendiendo por salud mental como el estado de bienestar que permite a los individuos realizar sus habilidades, afrontar el estrés normal de la vida, trabajar de manera productiva y fructífera, y hacer una contribución significativa a sus comunidades" (OMS, 2002).

Además, López, H (2011) sostiene que existe bastante desconocimiento entre ellos sobre esta patología pues, cuando caen en una situación de desgaste profesional, no se explican los síntomas que sufren. Por lo tanto, es preciso ofrecer a los presbíteros información pertinente sobre los riesgos y consecuencias de este fenómeno, con el fin de promover mejores condiciones laborales y poder así prevenir el síndrome de quemarse por el trabajo. Como contraparte a un mejor manejo del desgaste profesional es preciso hacer referencia también al desarrollo de capacidades de autocuidado para la protección de la salud en general. Proporcionar a los sacerdotes capacitación para el desarrollo de aptitudes y conductas que les ayuden a modificar sus estilos de vida, con el fin de que ellos establezcan prácticas apropiadas de autocuidado, y así preservar mejor su salud física, mental y espiritual.

Algunos sacerdotes de la muestra, manifestaron que han recurrido a la utilización de ansiolíticos, o que fueron disminuyendo el ritmo de actividad, tomando vacaciones, compartiendo en familia, a través de la recreación musical, aislándose, realizando retiros espirituales, relacionándose con la comunidad, y la esperanza también como una salida a los conflictos. Muchas de estas ayudas a las que recurren pueden también funcionar como factores protectores. López, $\mathrm{H}$ (2011) como resultado de su investigación propone que la Iglesia Católica ponga al servicio de los presbíteros una pastoral sacerdotal, al igual que 


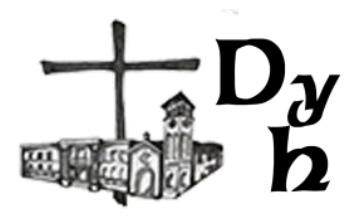

aquellas que existen para los fieles (juvenil, matrimonial), para colaborar en la prevención del desgaste provocado por la superposición de tareas, reforzando de alguna manera el autocuidado, aspecto que en el presente trabajo se considera de vital importancia, siendo reflejado claramente en las expresiones de los sacerdotes de la Diócesis de Argentina.

La autora continúa diciendo que también se debe reforzar el cuidado de la salud de los sacerdotes, así como ayudas concretas en aspectos tales como la revisión de la situación económica y las necesidades de recreación con las que cuentan los sacerdotes. Dificultades que se evidencian claramente en los sacerdotes de la Diócesis de Argentina, como factores generadores de estrés, preocupación y desgaste. Así la OMS (2002) nos dice que entre otros factores psicosociales ligados a la protección de la salud y la promoción en adultos figuran el vínculo seguro y firme, una visión optimista de la vida y un sentido de propósito y dirección, estrategias efectivas para hacer frente a los desafíos, un control consciente de los acontecimientos de la vida, relaciones emocionales gratificadoras, expresión de emociones positivas e integración social. Existe considerable evidencia de que las estrategias preventivas mejoran la vida de relación y ocupacional. La prevención del Burnout implica contrarrestar tanto los factores de riesgo como a los mecanismos mediante los cuales dichos factores producen el síndrome, en los que está implicada la interacción entre las características personales y el ambiente de trabajo.

En el síndrome de Burnout se ven implicadas múltiples y diversas variables, lo que dificulta su intervención. Se ha apuntado a realizar modificaciones en el trabajador como individuo afectado por algún defecto en su carácter o en su conducta (Gascón, S et al 2003). Frente a esta postura, Leiter, M y Maslach, C (1988) consideran al síndrome como responsabilidad del medio social en el que se trabaja, ya que lo que resulta problemático es el desajuste entre el trabajador y su medio laboral. De ahí que para estos autores la intervención no debe centrarse en el individuo aislado, sino en la sobrecarga laboral, las recompensas (no sólo económicas), el grado de control sobre la tarea, el sentimiento de comunidad, la presencia o ausencia de equidad y el conflicto entre los propios valores y los de la empresa u organización. Este trabajo sobre la organización tiene más posibilidades de lograr un cambio efectivo frente al estrés, al dirigir las soluciones al grupo, construyendo un 
proceso de apoyo mutuo entre los compañeros. Por lo tanto, la idea crucial de esta investigación es la de reforzar el autocuidado en los sacerdotes, trabajar sobre todo los saberes o preconceptos que se tienen en torno al imaginario social de un sacerdote que todo lo puede. Los resultados obtenidos servirán como guía para generar acciones tendientes a realizar comparaciones con otras diócesis, ampliando la muestra para observar qué hallazgos se mantienen y cuáles son diferentes y a qué se deben.

\section{Referencias bibliográficas}

Alves de Morais, F. 2008. "Stress, burnout, coping em padres responsáveis pe la formação de seminaristas catóicos. Tese apresentada à Pontificia Universida de Catóica de São Paulo, como exigência parcial para obtenção do título de Doutor em Ciências da Religião". São Paulo..

Crea G. 2012. Stress e Burnout Negli Operatori Pastorali. Italia. Ed.Giunti

Cozzens D. 2000. The Changing Face of the Priesthood. Order of Saint Benedict. The Liturgical Press. Collegeville, Minnesota (U.S.A).

Cucco García, M, “Una propuesta de intervención sobre malestares de la vida cotidiana. Del desatino social a la precariedad narcisista". Ed Atuel. Ediciones Pirámide; 2006.

Facal Fondo, T. 2012. Prevalencia del Síndrome de Burnout en trabajadores sociales de los servicios sociales comunitarios. España. Ed. Universidad de Huelva.

Gil-Monte, P. El Síndrome de Quemarse por el Trabajo. Madrid, España; 2006.

Gil-Monte, P. R., Peiró, J. M. y Valcárcel, P. A. 1998. Model of Burnout process development: Analternative from appraisal models of stress. Comportamento Organizacional e Gestao, 4(1):165-179.

Gil Monte P. 2002. Influencia del género sobre el proceso de desarrollo del Síndrome de quemarse por el trabajo (burnout) en profesionales de enfermería. Psicología em Estudo, Vol. 7, págs. 3-10.

Gil-Monte PR. El Síndrome de quemarse por el trabajo (burnout). Una enfermedad laboral en la sociedad de bienestar (Neira, 2004). Madrid: Pirámide; 2005. 


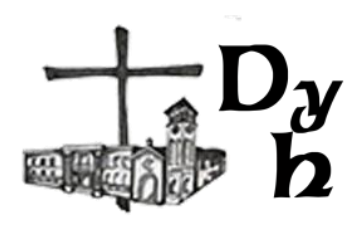

Grün, A. 1993. Fluir. Cómo superar el Burnout y los bloqueos. Ed. Salterrae. 2013. Schaufeli, W.B., Maslach. C. y Marek, T. Professional burnout:

Recentdevelopments in theory and research. London: Taylor \& Francis.ax. Lakoff, George y Rockridge Institute (s.f.) ThinkingPoints: Communicating our American Values and Vision. 2012. http://www.cognitivepolicyworks.com/wordpress/wpcontent/uploads/ThinkingPoints-BETA1.pdf.

Maslach, C. Golberg, J. 1983. Prevention of Burnout: new perspectives. Appliade \& Preventive Psichology, 7. Pp, 63-74.

Maslach C, Jackson. 1981. SE MBI: Maslach Burnout Inventory, Universidad de Salamanca, Manual. Palo Alto: University of California, Consulting Psychologists Press.

Melguizo, G. Integralidad y continuidad de la formación inicial y permanente del ministro ordenado. Medellín, 28 (109), 5-20. 2002.

Neira, M. 2004. Cuando se enferman los que curan. Estrés laboral y Burnout en profesionales de la salud, Buenos Aires: GambaCop.

Organización Mundial de la Salud. Fortalecimiento de la salud mental. 2000. Resolución del Consejo Ejecutivo de la OMS, Ginebra, EB109.R8. 2002. Cozzens D. The Changing Face of the Priesthood. Order of Saint Benedict. The Liturgical Press. Collegeville, Minnesota (U.S.A).

Paredes, M. 2001. Caracterización multivariante del Síndrome de Burnout en la plantilla docente de la Universidad de Salamanca. Memoria para optar al grado de Doctor. Departamento de Estadística. Universidad de Salamanca.

Strazdins, L. 2002. "Emotional work and emotional contagion". pp. 232-250. Londres: M. E. Sharpe.

Zanotti de Savanti A. 2013. Pensar las crisis en la vida sacerdotal y consagrada. Buenos Aires. Agape libros. 